\title{
THE STUDY OF WATERSHED TOPOGRAPHY CHARACTERISTICS IN VAKHSH RIVER BASED ON ZY3-DSM
}

\author{
Yajun Cui ${ }^{1, *}$, Lijun Chen ${ }^{2}$, Mengmeng $\operatorname{Li}^{1}$, Zecheng Men ${ }^{1}$ \\ ${ }^{1}$ China University of Mining and Technology, Beijing 100083, China - cuiyajun9@163.com \\ ${ }^{2}$ National Geomatics Center of China, Beijing 100830, China
}

Commission III, WG III/1

KEY WORDS: ZY3-DSM, the Catchment Boundary Profile Line, the Longitudinal Valley Profile Line, the Terrain Complexity Indices, the Landform Development Indices

\begin{abstract}
:
The Vakhsh River is one of the major rivers in Tajikistan. The quantitative analysis of watershed topography and developmental characteristics in Vakhsh River catchment can reflect the morphological characteristics of the region, which is of great significance for revealing the quantitative relationship between the hydrological and the geomorphological process. In this paper, the D8 algorithm and the spatial analysis method were used to extract the river networks, the catchment boundary profile lines and the longitudinal valley profile lines of the four major tributaries in the Vakhsh River from the ZY3-DSM of 10 meters resolution. On this basis, five quantitative indices including the frequency of wave, amplitude of wave, gully density, the longitudinal slope and roundness rate were used to analyze the watershed landform and its development degree. According to the experimental results, the catchment have a high surface complexity and a mature landform. Yovonsu river catchment which is in the downstream of Vakhsh River is oval and has low terrain complexity with large frequency and small amplitude. Among the midstream and upstream, the Mukson River has developed into geriatric terrain that is the most mature and has the highest surface complex, while the Obikhingon River and the Kizilsu River have developed into a stable maternal terrain. In terms of topography, the boundary elevation of the Obikhingon is basically in accordance with the normal distribution, while the Kizilsu and the Muksu show a peak state with elevations of 4,000-5,000m and 5,000-5,500m, respectively.
\end{abstract}

\section{INTRODUCTION}

Geomorphology refers to the geometric features of the surface, which not only has a typical spatial distribution, but also shows a relatively independent feature in a certain range (Wang and Qin, 2017). Based on the watershed, it is expected to reflect the geomorphic characteristics from the perspective of watershed geomorphology by studying the landform and development characteristics of a certain area.

Much work has been done in relation to the quantitative study of the geomorphic characteristics of the watershed. According to previous research, the terrain profile line which directly reflects the terrain relief is widely applied in the study of watershed erosion development to regional landform types on macro scale. The shape of transverse profiles reflects erosional processes (Harbor and Wheeler, 1992; Schumm et al., 1995). The longitudinal profiles of watersheds have often been linked to erosional power, aggradations and tectonics (Lu et al., 1998; Snyder et al., 2003). The spatial distribution and propagation mechanism of the gully nodes in the longitudinal valley profile reflect the development stage of the geomorphology (Lin and Oguchi, 2009; Hayakawa and Oguchi, 2009; He et al., 1999). Nevertheless, the longitudinal valley profile is hard to reveal the topography of positive terrain. Tang et al. (2009) proposed the concept of the catchment boundary profile line. The catchment boundary profile line with the certain spatial position, can effectively reflect the basic terrain features of the basin. According to the catchment boundary profile spectrum, the morphological characteristics and development mechanism of the Loess landforms were revealed from different sides (e.g., Jia, 2010; Zhang, 2011). The catchment boundary is the highest marginal line in the entire basin and is almost not affected by the erosion of waterflow. Its landform is stable, which not only reflects the characteristics of geomorphic tectonic movement, but also reflects the overall peripheral structure of the landform of the basin. Meanwhile, the valley is formed by erosion of waterflow, which can be affected easily and is the most active part of the watershed geomorphology. Its development affects the erosion and accumulation of basin, which can depict the development characteristics and stages of the basin. Therefore, quantitative analysis of the catchment boundary profile spectrum and the longitudinal valley profile spectrum at the same time can reflect the geomorphological features and development characteristics of the basin as a whole.

The Vakhsh River in Tajikistan was used as a case study in this paper. The formation mechanism of the river runoff in Tajikistan has its own unique characteristics, mainly based on precipitation and glacier melting. This study provides a reference for understanding the rivers in Tajikistan and studying the characteristics of the basins in the high-cold mountains.

* Corresponding author 


\section{MATERIALS AND METHODS}

\subsection{Study Area and Data}

The Vakhsh River rises in the mountains and is one of the main rivers in Tajikistan. The Vakhsh River that is formed by the confluence of the Kizilsu River and the Muksu River, is 566 kilometers in length. And it has a drainage area of $38,800 \mathrm{~km}^{2}$ approximately, which accounts for $1 / 4$ of the land area of Tajikistan. The total drop is 1,528 meters and the runoff is mainly supplied by melting snow and glaciers. In this paper, the Kizilsu, Muksu, Obikhingon and Yovonsu River that are the tributaries in the upstream, midstream and upstream respectively were as the research objects (Figure 1).

The ZY-3 is the first civilian high-resolution stereoscopic Earth mapping satellite of China. It carries forward looking, downward looking, backward looking cameras and a multispectral camera which are used to acquire three stereoscopic images and stereo pairs. The research data of the experimentation area is a kind of digital surface model of $10 \mathrm{~m}$ resolution obtained by automatic matching with multi model and multi baseline algorithms by using ZY-3 satellite images.

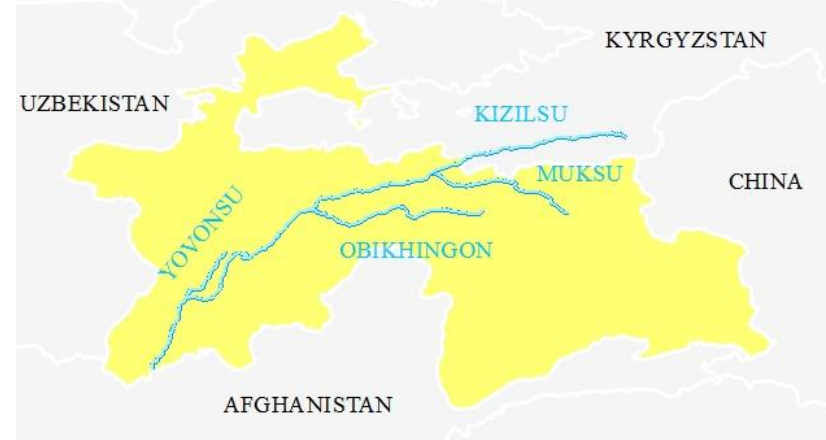

Figure 1. The location of the Vakhsh River

\subsection{Methodology}

In this study, D8 algorithm and basin analysis were used to obtain the drainage network of the Vakhsh River and the catchment boundary line of four tributaries (Figure 2). Then, we took the turning points on the profile lines as the sampling points and extracted the elevation of each sampling point based on ZY3-DSM. For analysis, the spectrums start from the outlet point of catchment, and regard the sampling point sequence and the sampling point elevation as the $\mathrm{X}$ value and $\mathrm{Y}$ value respectively. The experimental process is shown in Figure 3.

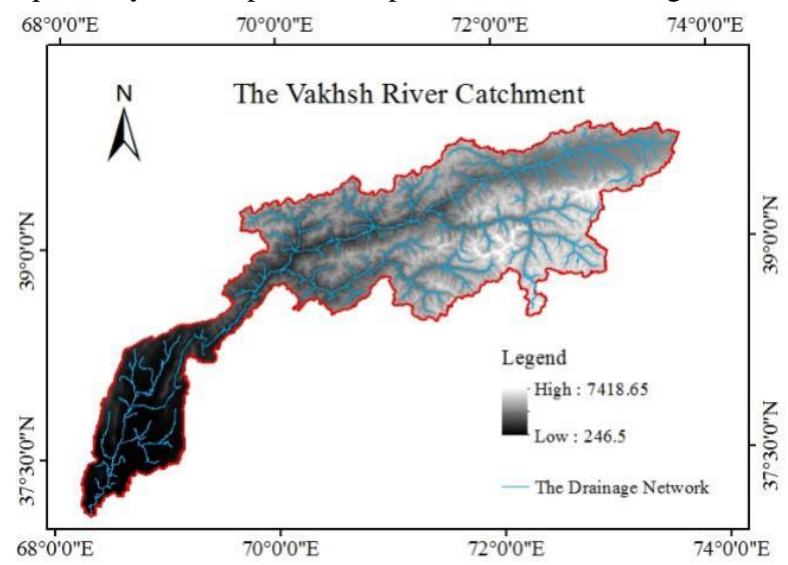

Figure 2. The river network distribution of the Vakhsh River

\section{QUANTITATIVE INDICES}

The quantitative index system based on the catchment profile spectrum is constructed from the terrain complexity and the landform development.

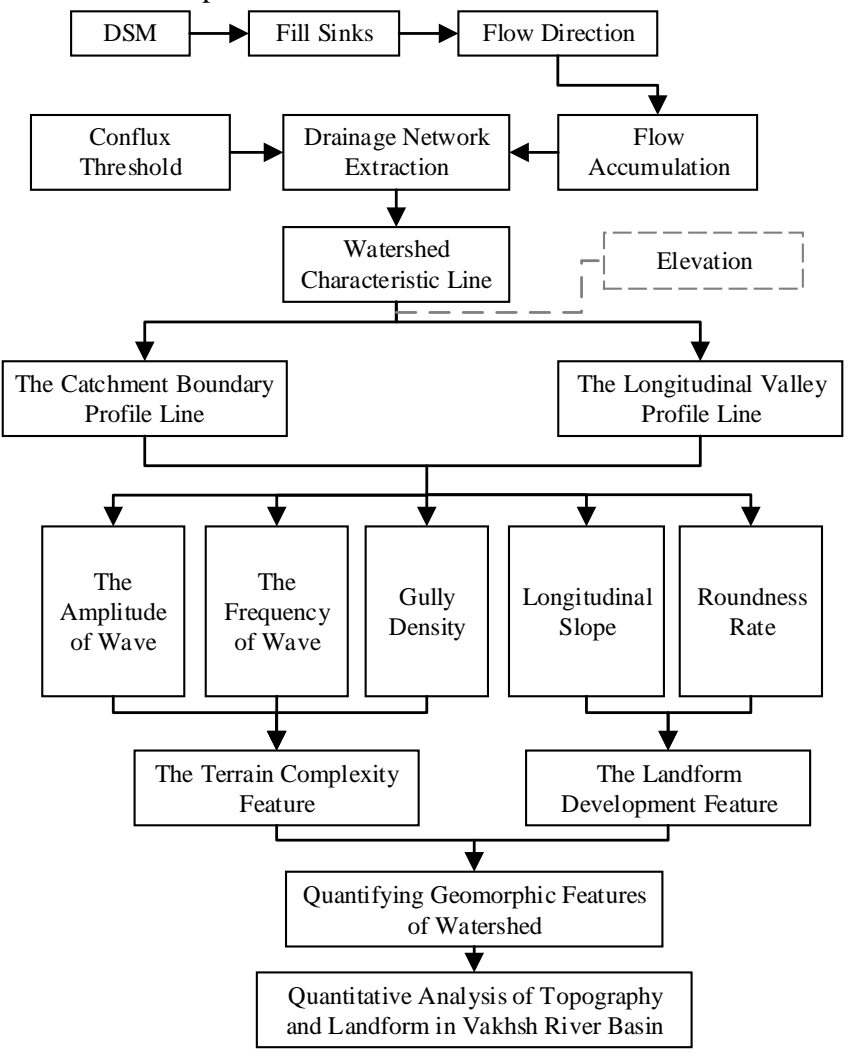

Figure 3. Experimental scheme

\subsection{The Terrain Complexity Indices}

The terrain complexity indices are the parameters to evaluate the relief amplitude and the degree of fold, which can used to describe quantitatively the boundary profile line and river network of different watershed. Three quantitative indices were selected including the frequency of wave, amplitude of wave and gully density to describe the morphological characteristics of the four catchment boundaries, and then to reflect the relationships and differences among the four watersheds.

(1) Amplitude (W)

The amplitude of catchment boundary spectrum is the difference between the elevation of the wave crest (wave trough) and the mean value of the wave trough (wave crest) on both sides of the wave crest (wave trough) in the following formula:

$$
\mathrm{W}=\left|\mathrm{Y}_{\mathrm{i}}-\frac{\left(\mathrm{Y}_{\mathrm{i}-1}+\mathrm{Y}_{\mathrm{i}+1}\right)}{2}\right| /\left(\mathrm{X}_{\mathrm{i}+1}-\mathrm{X}_{\mathrm{i}-1}\right)
$$

Where $\quad Y_{i}, Y_{i-1}, Y_{i+1}=$ the elevation of sample point

$\mathrm{X}_{\mathrm{i}-1}, \mathrm{X}_{\mathrm{i}+1}=$ the sequence of sample point

(2) Frequency (F)

The frequency of catchment boundary spectrum is the ratio of the number of wave crest and wave trough to the sample number in the following formula:

$$
\mathrm{F}=\left(\mathrm{N}_{\mathrm{wc}}+\mathrm{N}_{\mathrm{wt}}\right) / \mathrm{N}_{\mathrm{s}}
$$


Where $\quad \mathrm{N}_{\mathrm{wc}}=$ the number of wave crest

$\mathrm{N}_{\mathrm{wt}}=$ the number of wave trough

$\mathrm{N}_{\mathrm{s}}=$ the sum of sample points

(3) Gully Density (Ds)

Gully Density is the total length of ravine in a unit area in the following formula:

$$
\mathrm{D}_{\mathrm{s}}=\left(\sum \mathrm{L}\right) / \mathrm{A}
$$

Where $\quad \sum \mathrm{L}=$ the total length of the gully in watershed $\mathrm{A}=$ the catchment area

\subsection{The Landform Development Indices}

The landform development indices can reflect the characteristics of regional tectonic deformation. Two quantitative indices were selected including the longitudinal slope and roundness rate to quantitatively describe the landform development, and then to reflect the relationships and differences among the four watersheds.

\section{(1) Longitudinal Slope (J)}

The longitudinal slope is the ratio of the elevation difference between the source point and the outlet to the length of the main valley, which is the longitudinal gradient of the river in the following formula:

$$
J=\left(H_{\max }-H_{\min }\right) / L
$$

Where $\quad \mathrm{H}_{\max }=$ the highest elevation of the valley

$\mathrm{H}_{\min }=$ the elevation value of the drainage outlet $\mathrm{L}=$ the length of the valley

(2) Roundness Rate (C)

Roundness Rate is the ratio of the catchment area to the circular area with the same perimeter as the boundary in the following formula:

$$
\mathrm{C}=\mathrm{A}_{\mathrm{b}} / \mathrm{A}_{\mathrm{c}}
$$

Where

$$
\begin{aligned}
& \mathrm{A}_{b}=\text { the catchment area } \\
& \mathrm{A}_{\mathrm{c}}=\text { the circular area with the same perimeter as } \\
& \text { the catchment boundary }
\end{aligned}
$$

\section{RESULTS}

\subsection{The Catchment Profile Spectrums}

The catchment boundary profile line and the longitudinal valley profile line have a specific morphology in the specific development stage, which change with time and have the characteristics of geomorphic correspondence. Therefore, the geomorphic features can be expressed intuitively by describing the shape of the catchment profile spectrums. The elevation distribution of catchment boundary and the catchment profile spectrums of four tributaries in the Vakhsh River as shown in Figure 4 and Figure 5 respectively. The basic geographic attributes of the four catchment boundaries are shown in Table 1.

\begin{tabular}{|c|c|c|c|c|c|c|c|c|}
\hline Watershed & $\begin{array}{c}\text { Watershed } \\
\text { Area }\left(\mathrm{km}^{2}\right)\end{array}$ & $\begin{array}{c}\text { Minimum } \\
(\mathrm{m})\end{array}$ & $\begin{array}{c}\text { Maximum } \\
(\mathrm{m})\end{array}$ & Mean $(\mathrm{m})$ & $\begin{array}{c}\text { Standard } \\
\text { Deviation }(\mathrm{m})\end{array}$ & $\begin{array}{c}\text { Elevation } \\
\text { Difference }(\mathrm{m})\end{array}$ & Kurtosis & Skewness \\
\hline Yovonsu & 2166.05 & 354.8600 & 2255.3401 & 1362.9689 & 466.9151 & 1900.4801 & -0.0969 & -0.7569 \\
\hline Kizilsu & 8345.49 & 1803.2500 & 7051.8901 & 4456.8706 & 859.0864 & 5248.6401 & 1.6395 & -0.3352 \\
\hline Muksu & 6896.21 & 1803.3101 & 7416.4800 & 5010.0481 & 1053.8724 & 5613.1699 & 2.1047 & -1.4201 \\
\hline Obikhingon & 6589.44 & 1109.8700 & 7416.4800 & 3994.3031 & 1059.4298 & 6306.6100 & 0.0884 & 0.0938 \\
\hline
\end{tabular}

Table 1. The basic geographic attributes
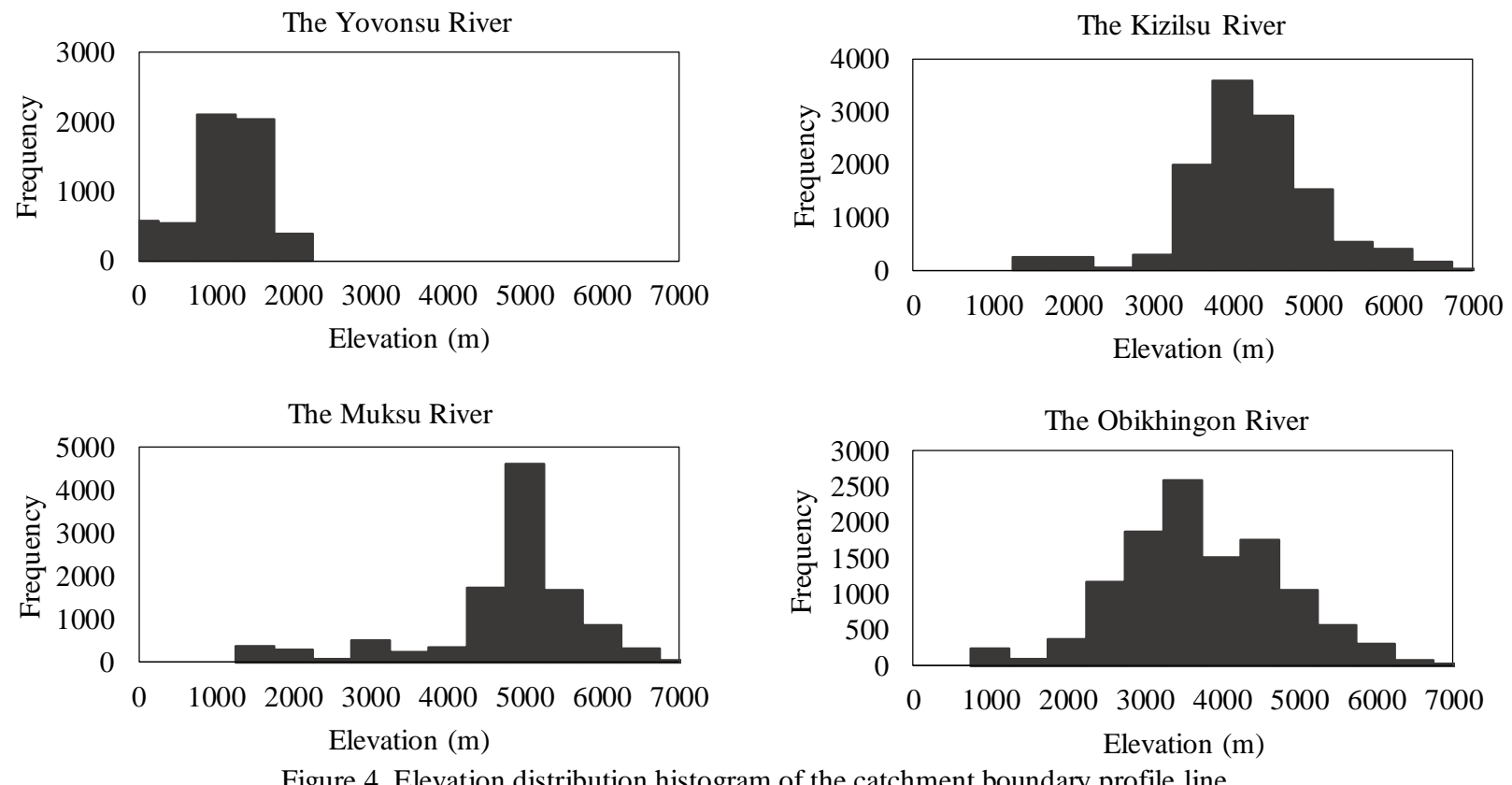

Figure 4. Elevation distribution histogram of the catchment boundary profile line 
From the trend of the boundary lines of the four watersheds, the profile lines is basically bilateral symmetry. The elevations of the boundary profiles of the Yovonsu River are increasing gradually from the outlet to the highest point and then show an obvious fluctuation after that. The reason is that the Yovonsu River flows through the broad valley covered with cotton fields and soil with small elevation fluctuation. In addition, the other three boundary profile lines have a sustainable rapid rise of the elevations in the process of the sides to the middle. The Kizilsu, Muksu and Obikhingon River are all located in the deep mountain valley. Therefore, from the watershed outlet to the negative terrain, there are large span and steep slope. After the elevation increased sharply, the catchment boundary profile lines maintain a steady state of fluctuation. The feature corresponds to the surface fluctuations due to the strong erosion and transportation of mature area. In the area bordered the Kizilsu River Basin and the Muksu River Basin, the surface undulation is relatively large and there is a clear concave due to serious erosion. Accordingly, a new valley is about to be formed at the lower notch.

The Yovonsu River

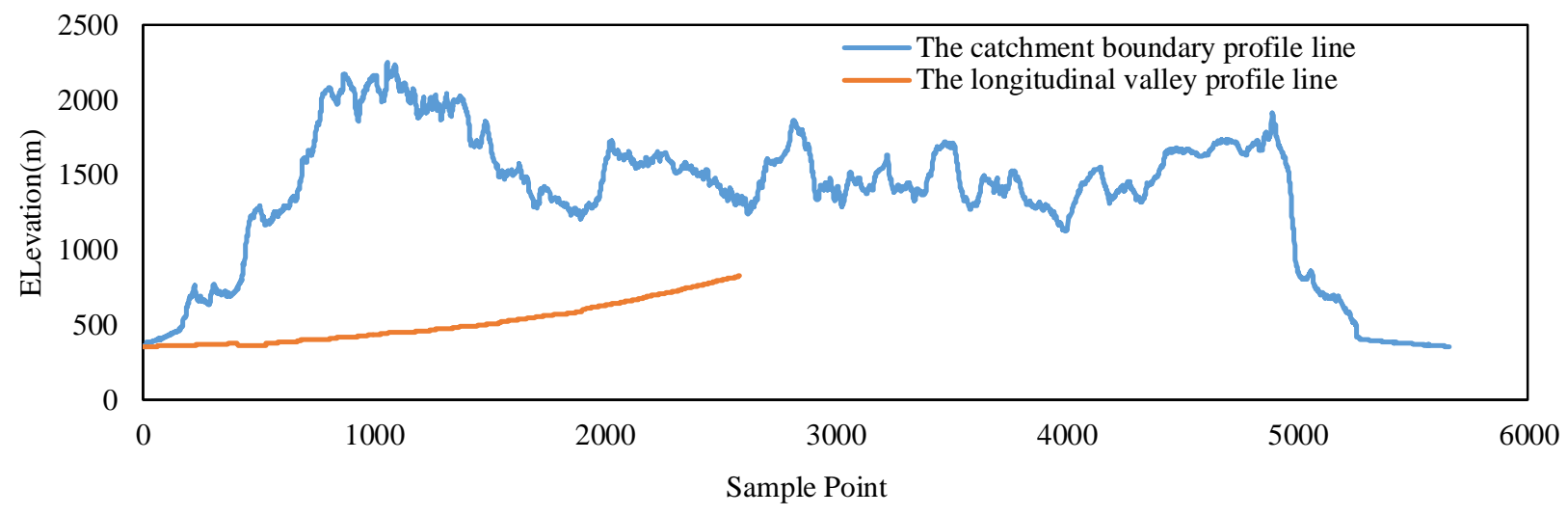

The Kizilsu River

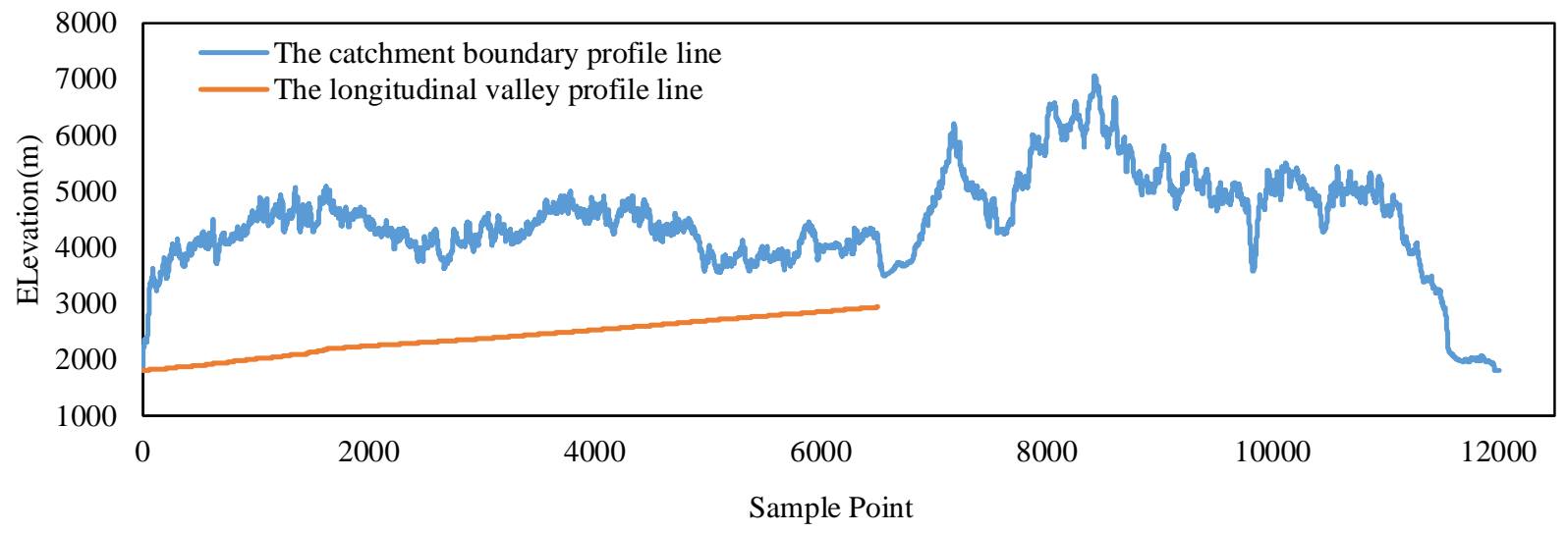

The Muksu River

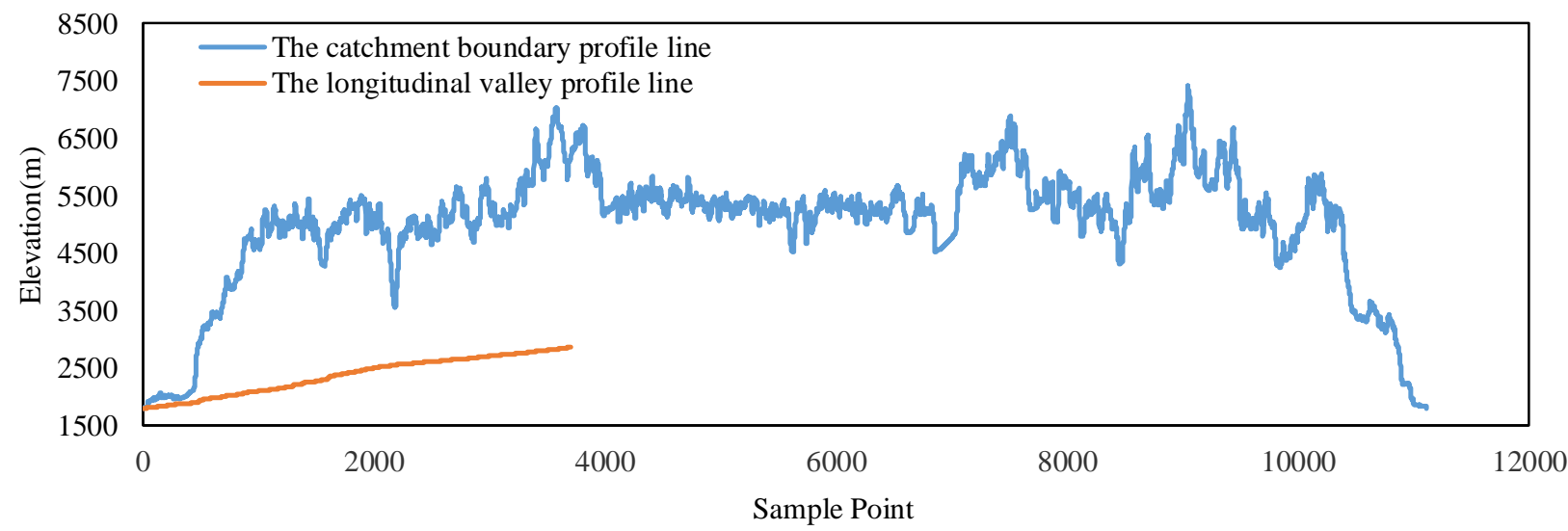


The Obikhingon River

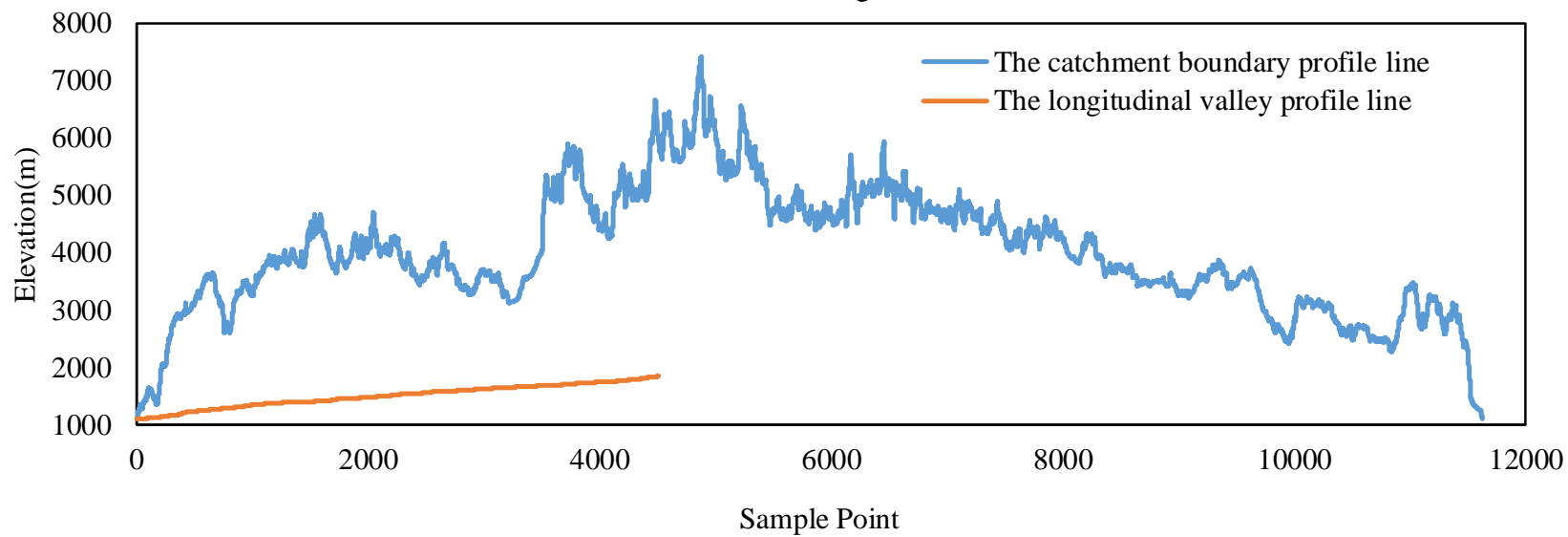

Figure 5. The catchment profile spectrums of four tributaries

According to the elevation distribution histogram of catchment boundary profile line, histogram of the Yovonsu River shows a low kurtosis. The Kizilsu River and the Muksu River have obvious high kurtosis. The histograms all have an exclusive rectangular band, indicating that the elevation of the boundary profile lines are concentrated in the ranges of $4,000-5,000 \mathrm{~m}$, $5,000-5,500 \mathrm{~m}$ respectively, which reflects the top part of the catchment boundary profiles remain stable relatively. Because the elevations of the two basins are concentrated, the profile lines keep monotonicity from the outlet to the first local surface peak. And the boundary elevation of the Obikhingon River is tally with the normal distribution basically, which results in the small kurtosis and skewness.

As can be seen from the longitudinal valley profile line of four tributaries, the whole shape of the lines are similar to that of power function. The longitudinal profile line of main valley can be expressed by the equation of $\mathrm{y}=\mathrm{ax}^{\mathrm{N}}$, which takes the outlet as the origin, where $\mathrm{N}$ can indicate the concavity of the longitudinal valley profile (Li et al., 2017). In terms of the fitting analysis of the longitudinal valley profile line with power function, the Obikhingon River have developed into deep erosion period, while the Kizilsu River have developed into the transitional stage between incised erosion and graded adjustment. The Yovonsu River and the Mukson River have developed into a stable stage.

\subsection{Analysis on Quantitative indices}

The fluvial geomorphology is formed by soil erosion and accumulation. The differences in morphology reflect the erosion scales and geomorphic evolutions.

4.2.1 The Terrain Complexity Analysis: Topography is a significant underlying surface factor that affects water erosion. Therefore, studying the terrain complexity plays an important role in exploring water erosion and landform development. The indices of the four basins are shown in Figure 6. In general, the greater amplitude of wave the higher surface complexity. In the same physiognomy type areas, the amplitude keeps similar. Meanwhile, it is affected by the individual particularity of the catchment. As shown in Figure 6, the Kizilsu River, the Muksu River and the Obikhingon River have large amplitude, indicating that the surface complexity of the basin is relatively high. Among them, the Muksu River has the highest degree of undulation, which corresponds to the disparity of elevation distributions in the histogram of the boundary. The amplitudes of the Kizilsu River and the Obikhingon River are similar, indicating that the terrain complexity and the change of the boundary profile lines are similar. The Yovonsu River has small amplitude, which is located in the wide valley with little elevation fluctuations. The frequency of wave of the four basins are similar, and the mean value is about 0.0552 . From the aspect of gully density, the four basins are basically in the stable stage. With the side erosion of the river, channel becomes wider and terrain gradually becomes flatter so that the gully density are small.

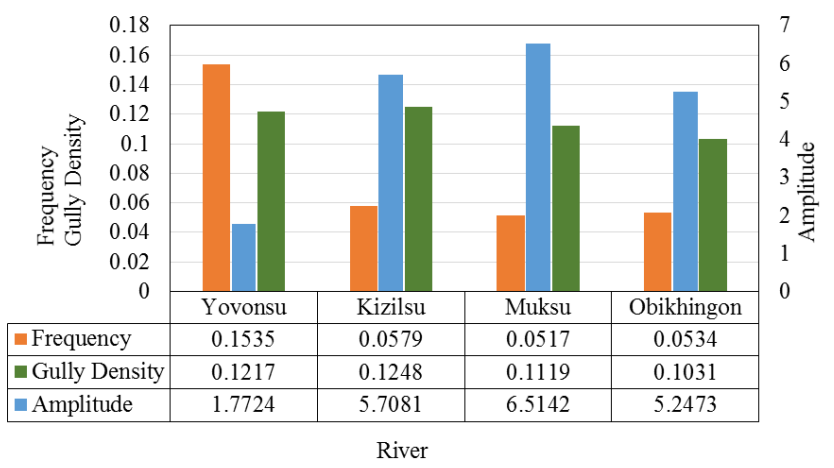

Figure 6 . The terrain complexity indices

4.2.2 The Landform Development Analysis: The correlation between geomorphologic development and water erosion can be reflected quantitatively from different aspects by landform development indices. The indices of the four basins are shown in Figure 7. The longitudinal slope of the Yovonsu River is small because of stability and low terrain. And the Kizilsu River with large area has numerous tributaries so that the value is also small. Dissimilarly, the other two basins are located in the deep valleys and have large downcutting depth, so the longitudinal slope of them are large. The roundness rate is not only influenced by lithology, but also depends on the development degree of the basin and the total slope of the region. Judging from the entire Vakhsh River, the development of catchment is relatively mature. From the catchments of four tributaries, the development degree of the Yovonsu River and the Muksu River are lower than that of the Kizilsu River and the Obikhingon River. This is corresponding to the overall situation of the longitudinal valley profile lines. 


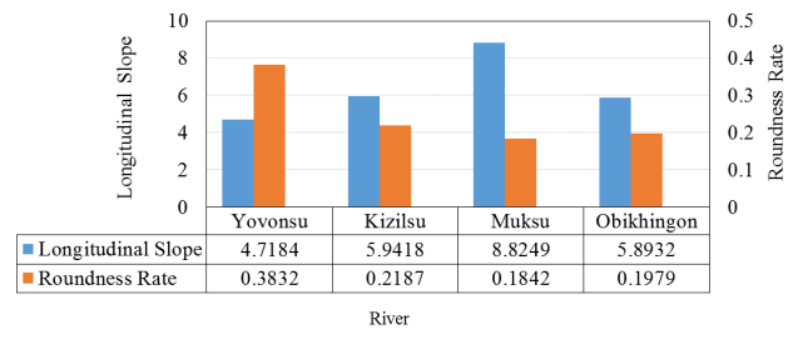

Figure 7. The landform development indices

\section{CONCLUSIONS}

Based on the four main tributaries of the Vakhsh River as the study area, the basin geomorphological characteristics have been studied by using the methods of digital terrain analysis and mathematical statistics. The experimental results show that:

(1) According to the catchment boundary profile spectrum and elevation distribution histogram, the elevation of the Yovonsu River border is in a steady fluctuation, which is relatively uniform. Besides, the amplitude of the topography is small. By contrary, the spectrum of other three tributaries have a sustainable rapid rise of the elevations in the process of the sides to the middle. After the dramatic increase of the elevation, the catchment boundary profile spectrum maintains a steady state of fluctuation. Among them, the boundary elevation of the Obikhingon River is tally with the normal distribution basically, while the Kizilsu River and the Mukson River show the peaks with elevations of $4,000-5,000 \mathrm{~m}$ and $5,000-5,500 \mathrm{~m}$ respectively.

(2) In terms of the fitting analysis of the longitudinal valley profile line with power function, the Obikhingon River have developed into deep erosion period, while the Kizilsu River have developed into the transitional stage between incised erosion and graded adjustment. The Yovonsu River and the Mukson River have developed into a stable stage.

(3) After analyzing the watershed landform and its development degree by five quantitative indicators, the gully density of the four tributaries remain consistent, with an average value of 0.1154 . In addition, The Yovonsu River catchment in the downstream of Vakhsh River is oval and has low terrain complexity with large frequency and small amplitude, which is side-erosion mainly. By contrast, other three tributaries in the midstream and upstream of the catchment are narrow. Among them, the Mukson River has developed into geriatric terrain and it is the most mature area. Also it has the most complex surface with large amplitude and erosion. The Obikhingon River and the Kizilsu River have developed into a stable mature terrain and the amplitude of 5.2473 and 5.7081 respectively.

\section{REFERENCES}

Cai, L.Y., Tang, G.A., Xiong, L.Y., Kamilia, J.L., Xie, Y.T., Li, Y. P., 2014. An Analysis on Fractal Characteristics of Typical Landform Patterns in Northern Shaanxi Loess Plateau Based on DEM. Bulletin of Soil and Water Conservation, 34(3), pp. 141144.

Gou, W.T., Zhai, Q.Y., Yu, S.Y., Han, P.F., Li, X.Q., 2016. The Explore Base on Ziyuan-3 Satellite Imaging in the DSM Data Production. Geomatics \& Spatial Information Technology, 39(1), pp. 141-146.
Harbor, J.M., Wheeler, D.A., 1992. On the Mathematical Description of Glaciate Valley Cross-Sections. Earth Surface Processes and Landforms, 17, pp. 477-485.

Hayakawa, Y.S., Oguchi, T., 2009. GIS Analysis of Fluvial Knickzone Distribution in Japanese Mountain Watersheds. Geomorphology, 111(1-2), pp. 27-37.

He, Y., Jia, T.F., Li, R.Q., 1999. Development of Gullies and Evaluation on Their Stability in the Loess Hill Region. Arid Land Geography, 22(2), pp. 64-70.

Jia, Y.N., 2010. The Catchment Boundary Profile Spectrum Based on DEMs in Loess Plateau. Nanjing Normal University, Nanjing, China.

Li, C.R., Li, F.Y., Ma, J., Liu, W., 2017. The Study of Watershed Topography Characteristics in the Middle Reaches of the Yellow River. Geography and Geo-Information Science, 33(4), pp. 107-112.

Lin Z., Oguchi T., 2009. Longitudinal and Transverse Profiles of Hilly and Mountainous Watersheds in Japan. Geomorphology, 111, pp. 17-26.

Liu, X., Wang, L., Gao, P.L., 2011. Extraction of Stream Runoff Nodes Based on Geometric Network. Science of Surveying and Mapping, 36(5), pp. 85-86.

Lu, Z.C., 1998. River Bed Longitudinal Profile Morphology of the Lower Yellow River and its Implication in Physiography. Geographic Research, 22(1), pp. 30-38.

Schumm, S.A., Boyd, K.F., Wolff, C.G., Spitz, W.J., 1995. A Ground-water Sapping Landscape in the Florida Panhandle. Geomorphology, 12, pp. 281-297.

Shen, Z.Y., Li, Z.B., Li, P., Lu, K.X., 2009. Multiracial Arithmetic for Watershed Topographic Feature. Advances in Water Science, 20(3), pp. 385-391.

Snyder, N.P., Whipple, K.X., Tucker, G.E., Merritts, D.J., 2003. Channel Response to Tectonic Forcing: Filed Analysis of Stream Morphology and Hydrology in the Mendocino Triple Junction Region, Northern California. Geomorphology, 53, pp. 97-127.

Tang, G.A., Jia, Y.N., Qumu, W.Z., 2009. The Terrain Analysis Based on Profile Line of Catchment Boundary of Loess Landform. 1st International Postgraduate Conference on Infrastructure and Environment.

Tang, G.A., Li, F.Y., Yang, X., 2015. Exploration and Practice of Digital Terrain Analysis on the Loess Plateau. Science Press, Beijing.

Wang, Y.W., Qin, C.Z., 2017. Review of Methods for Landform Automatic Classification. Geography and Geo-Information Science, 33(4), pp. 16-21.

Yuankun, X.J., Chen, X., Zhang, F.H., 2015. Study on the DSM Production and Application Based on Rapid Produces ThreeLine Array Images of ZY-3. Geomatics \& Spatial Information Technology, 38(6), pp. 111-113.

Yue, Q.X., Gao, X.M., Tang, X.M., 2016. ZY-3 DSM Generation Method Based on Semi-global Optimization. 
Geomatics and Information Science of Wuhan University, 41(10), pp. 1279-1285.

Zhang, W., 2011. The Catchment Profile Spectrum Based on DEMs in Loess Plateau. Nanjing Normal University, Nanjing, China.

Zhou, L., Takashi, O., 2006. DEM Analysis on Longitudinal and Transverse Profiles of Steep Mountainous Watersheds. Geomorphology, 78, pp. 77-89.
Zhou, Q.M., Liu, X.J., 2016. Digital Terrain Analysis. SciencePress, Beijing.

Zhou, T., Long, Y., Tang, G.A., Yang, X., 2006. A Fractal Method to Describe the Terrain Complexity Reflected by the Raster DEM. Geography and Geo-Information Science, 22(1), pp. 26-30. 